\title{
Toward a culturally sensitive conceptualization of resilience: Participatory research with war-affected communities in northern Uganda
}

\section{Sofie Vindevogel}

Ghent University

\author{
Alastair Ager \\ Columbia University
}

\author{
Julie Schiltz, Eric Broekaert and Ilse Derluyn \\ Ghent University
}

\begin{abstract}
Resilience research with war-affected populations has long conceptualized resilience as the absence of psychopathology and operationalized it by use of standardized measures. However, literature on resilience increasingly highlights the importance of also including indicators of positively valued functioning as well as contextually sensitive indicators of resilience. This study used a participatory approach to examine the contextual conceptualization of youth resilience in the aftermath of war in northern Uganda, as defined by groups of stakeholders (youths, parents, elders, leaders, teachers) in four communities. The results identify 40 indicators covering a multiplicity of domains of functioning. The rationales behind these indicators were clustered into the broad themes: progress, selfreliance, social connectedness, morality, health, and comfort. The findings suggest that positively and negatively valued aspects of functioning are both key to conceptualizing resilience, and indicate the importance of including contextually distinguished indicators. The findings further point to the role of individual and collective processes in the construction of resilience, and to the need to take into account the contexts wherein resilience is conceptualized and observed. This study generated contextually sensitive indicators of young people's resilience, which can be used, complementary to existing
\end{abstract}

Corresponding author:

Sofie Vindevogel, Department of Orthopedagogics, Ghent University, Henri Dunantlaan 2, B-9000 Gent, Belgium.

Email: Sofie.Vindevogel@UGent.be 
measures of functioning, to provide a more comprehensive and culturally sensitive view of youths' resilience in the wake of war adversity.

\section{Keywords}

culture, participatory research, resilience, Uganda, war-affected youth

Contemporary warfare across the world is characterized by systematic violence and abuse that encompasses disruption of multiple life domains and levels of the social fabric (Barenbaum, Ruchkin, \& Schwab-Stone, 2004; Williams, 2007). Young people living in war zones often endure a multitude of hardships, which can affect their psychosocial well-being in profound and persistent ways (Goodhand \& Hulme, 1999; Wisner \& Adams, 2002). In northern Uganda, a war between the government and the rebel group Lord's Resistance Army (LRA) continued for more than two decades. Between 1986 and 2006, the LRA kept the region under a reign of terror by applying war strategies that deliberately targeted civilians, including: attacks on villages, schools, refugee camps and trading centers; road ambushes; looting, maiming, and killing of numerous civilians; and the violent abduction and forced recruitment of minors. This violence left tens of thousands of Ugandan people dead, maimed, displaced, and deprived of basic needs and human rights (Coalition to Stop the Use of Child Soldiers, 2008). Families were massively evacuated into internally displaced persons (IDP) camps, and many children commuted daily to trading centers and towns in hopes of finding protection against atrocities and recruitment by the LRA (Annan, Blattman, \& Horton, 2006). It is estimated that the LRA forcibly conscripted over 25,000 minors into their ranks (Coalition to Stop the Use of Child Soldiers, 2008). During their time with the rebel group, many children were forced to participate in raids, wounding, and killings, often directed at their own families, friends, and neighbors in order to sever social ties and discourage children from escaping (Annan et al., 2006; Vindevogel et al., 2011). Following the Cessation of Hostilities Agreement in 2006, the LRA insurgency mainly shifted to the neighboring countries, initiating a long transition process towards sustainable peace in northern Uganda.

A substantial body of research has documented the psychological consequences that are commonly seen among war-affected youth, including symptoms of posttraumatic stress disorder, anxiety, and depression (Attanayake et al., 2009; Jordans, Tol, Komproe, \& De Jong, 2009). Despite consistently providing evidence for the formidable psychological impact of armed conflict, the findings show a large amount of variation in prevalence estimates of these symptoms between and within war-affected populations. Recently, several studies have further investigated these observed variations and have increasingly pointed to the absence of significant psychopathology and the unexpected high functioning of many young people during or soon after armed conflict (Betancourt \& Kahn, 2008; McAdam-Crisp, 2006; Tol, Song, \& Jordans, 2013). This is commonly referred to as "resilience." 
Various definitions of resilience are in circulation as a consequence of inherent ambiguities and hidden contradictions on the theoretical level (Kaplan, 2005; Ungar, 2011) and as a result of the proliferation of resilience-focused research, interventions, and policy frameworks (Ager, 2013; Barber, 2013; Layne, Warren, Watson, \& Shalev, 2007; Luthar, Ciccetti, \& Becker, 2000). Notwithstanding such variation, a common denominator of these definitions is that the concept of resilience refers to the manifestation of positively valued functioning and avoidance of negatively valued functioning despite threat of or exposure to significant adversity (Kaplan, 2005; Luthar, 1991). In most studies, resilience has been conceptualized as the absence of psychological distress that is expected to manifest following experience with warfare (e.g., posttraumatic stress disorder), and has typically been operationalized by use of standardized self-report mental health symptom checklists (Barber, 2013; Tol et al., 2013). This exemplifies the predominance of pathogenetic models of well-being in research on the psychosocial consequences of warfare. Studies that use the presence of positively valued functioning as indicators of resilience (e.g., mastery) have hitherto been scarcer.

Moreover, most studies on resilience in war-affected areas have applied Western-based research designs and instruments in culturally diverse research settings (Ager, 1997; Bolton \& Tang, 2002; Honwana, 1997; Summerfield, 1999). A recent research review by Tol et al. (2013) highlights, however, that the conceptualization and operationalization of resilience varies significantly across sociocultural contexts. In this regard, various resilience researchers such as Rutter (2005) and Ungar and Liebenberg (2011) emphasize the need to consider the context in which resilience is observed and the contextually specific ways in which it is expressed. The sociocultural context is believed to determine to a great extent how concepts such as resilience are framed, understood, and demonstrated (Kirmayer, Dandeneau, Marshall, Kahentonni Phillips, \& Jessen Williamson, 2012; Panter-Brick \& Eggerman, 2012; Tol, Jordans, Reis, \& de Jong, 2009; Wessells, 2012). The research of Akello, Reis, and Richters (2010), for instance, highlights the phenomenon of mimetic and mirroring expressions of resilience in northern Uganda, whereby experienced psychological distress is silenced as a function of social, contextual, and political influences. These influences contributed to children's reluctance to publicly talk about the distress they experienced and share their concerns with others in their networks, which was considered a sign of strength in this context. This points to the complex interaction of well-being with the contextual, sociocultural, and normative processes that shape the conceptualization and expressions of resilience. A current research priority to further the understanding of resilience in particular research settings is therefore to identify indicators of resilience in culturally sensitive ways (Tol et al., 2013; Ungar \& Liebenberg, 2011).

Despite many studies investigating the aftermath of conflict, however, to date relatively few have systematically examined the conceptualization and contextually valid indicators of resilience in war-affected settings such as northern Uganda. A study of Klasen, Oetingen, Daniels, Post, and Hoyer (2010) examined resilience 
in formerly recruited youth by assessing posttraumatic stress disorder, depression, and behavioral and emotional problems. Ager and colleagues' study in northern Uganda (Ager, Akesson, et al., 2011) showed recovery in self, parent, and teacher reports of well-being for youth serving as a comparison group for an intervention impact study of a school-based structured psychosocial activity program. Schultz, Sorensen, and Waaktaar (2012) investigated trauma exposure and mental health in adolescents, and reported resilience on the basis of the assessed PTSD symptoms, conduct problems, hyperactivity, prosocial behavior, and self-efficacy. Haroz, Murray, Bolton, Betancourt, and Bass (2013) studied the influence of perceived social support and prosocial behavior on resilience, which was operationalized as mental health symptom reduction using locally defined syndromes of depression and anxiety. In these few studies, the predominant focus remains on the absence of significant psychopathology as the principal indicator of resilience (Ager, Annan, \& Panter-Brick, 2013; Tol et al., 2013). Testing whether these indicators resonated with context-specific understandings of resilience was also secondary or peripheral in these studies (Tol et al., 2013).

This study therefore aimed to explore contextually grounded key indicators of young people's resilience in the aftermath of war in northern Uganda, wherein resilience was conceptualized according to the aforementioned definition as the manifestation of positively valued functioning and avoidance of negatively valued functioning despite encountered challenges. Extensive ethnographic research in northern Uganda has demonstrated that warfare has deeply marked sociocultural life in this area and has examined how people attempt to understand and cope with war experiences and postwar challenges (Atim \& Proctor, 2013; Finnström, 2008). We refer to such studies for a thorough analysis of the sociocultural context, against which we may interpret the conceptualization and indicators of resilience generated by the present study. This study aimed to contribute to the body of knowledge on local understandings of resilience in the aftermath of war and thereby further the conceptualization of resilience that incorporates both negatively and positively valued indicators of contextually grounded understandings of resilience. Given the current dearth of studies departing from a culturally sensitive conceptualization for monitoring resilience in this setting, this knowledge is a prerequisite for being able to assess resilience in northern Ugandan youth in a contextually meaningful, valid, and reliable manner. Alongside this potential scientific benefit, this study sought to empower local communities dealing with postconflict distress in young people, noting that the joint reflection and increased awareness of resilience indicators can strengthen communities and support resilience among young people.

\section{Methodology}

\section{Procedure}

In order to develop a contextually sensitive research design and maximize input from local stakeholders, we applied a participatory research approach (Ager et al., 
2013; Camfield, Crivello, \& Woodhead, 2009; Luthar et al., 2000). More specifically, a constellation of methods was selected from participatory rural appraisal, "a family of approaches and methods to enable rural people to share, enhance, and analyze their knowledge of life and conditions, to plan and to act" (Chambers, 1995 , p. 2). While initially developed for rural communities, these methods have been applied successfully in urban and peri-urban settings as well. To begin, existing structures of community representatives (mostly composed of leaders, elders, and youths) were consulted as an entry point to the villages and schools. With the assistance of these community representatives, a meeting was organized during which the research group and project were introduced to the community members. All prospective participants received information on the aims and procedure of the study, the ethical precautions that were taken, consequences of participation or refusal/withdrawal, and opportunities for feedback on the research and for psychosocial support. Next, the community representatives were invited to make a historic timeline of important events in the area and to construct a community map on which relevant resources (schools, roads, health centers, church, etc.) and all households were situated. This information was later used to conduct a transect walk in the village. During this walk, all households were visited to seek their consent to participate and to collect basic sociodemographic information. These steps were mainly undertaken to establish rapport with the community as well as to collect data for the stratified random sampling of participants for the participatory ranking method (PRM).

PRM was developed as a structured, participative method that generates elaborative qualitative and quantitative data on a central research question and that allows participants to express their understanding and to determine priorities according to their experience (Ager, Stark, Sparling, \& Ager, 2011). The method is focused around one key framing question and consists of three parts. In the absence of vernacular idioms of resilience, the key framing question was, "How do you identify young people in your community who are doing well despite the difficulties in their life?" The first part was the "pile," during which participants were asked to think of examples of young people they know who they consider to be doing well despite difficulties in their lives, and to describe the characteristics of those young people that led them to make that judgment. Clarifying paraphrases and probe questions were regularly used to facilitate elicitation of answers and discussion among the participants (e.g., How can you tell that he/she is doing well? Does everyone agree that this is important?). The question thus focused on young people in general and did not concern the participants' own situations. The participants were then invited to represent their answers by an object of their choice (e.g., coins, bottle caps, flowers, shoes) and place that object in the centre to start a pile of answers. This helped to visualize and thereby maintain the overview of the generated indicators. In the second "rank" part, the groups were asked which answers were most significant to one's well-being. The participants ranked the answers according to their importance by jointly positioning and repositioning the representative objects until a final ranking was agreed upon. It has been 
1. Preparatory meetings with community representatives and prospective participants

2. Creation of historic timeline and community map

3. Transect walk to collect informed consent and compose groups

4. Participatory ranking method (PRM)
a. Pile
b. Rank
c. Meaning

5. Concluding meetings with community representatives and participants

Figure I. Overview of the data collection procedure.

argued that conscious consideration of indicators' relative importance provides a different and probably more reliable evaluation than spontaneous listing (Stark, Ager, Wessells, \& Boothby, 2009). The third part of the PRM addressed the "meaning" that was obtained throughout the session by recording the explanations and motivations that the participants shared in order to rationalize their responses and to negotiate the pile and rank of objects. These qualitative data allowed us to contextualize and interpret the quantitative results of the pile and rank parts. The PRM sessions were conducted in a private space in the village or school by a team of two researchers and one translator (English-Lango). The first researcher filled the role of facilitator, while the second acted as note-taker. Afterwards, community meetings were organized during which the preliminary findings were presented by the researchers and discussed with the participants. No new indicators were brought up, nor were presented indicators contested. These community meetings gave the opportunity to feed back the findings to the participating communities to increase the local benefits of this study. Figure 1 provides an overview of the consecutive steps of the data collection procedure. The study design was approved by the Ethical Committee of the Faculty of Psychology and Educational Sciences of Ghent University.

\section{Study setting and participants}

The study was carried out in Lira district, Lango subregion in northern Uganda from September to October 2012. Along with the neighboring Acholi subregion, this area was among the most affected by the LRA insurgency. Four communities that had been randomly sampled for previous research (Vindevogel, De Schryver, Broekaert, \& Derluyn, 2013) were selected based on their location: one urban, one peri-urban, and two rural villages and their respective schools, all located at the epicenter of the LRA insurgency between 2000 and 2006. The preparatory construction of historic timelines and community maps revealed that the communities 
had experienced numerous attacks, raids, mutilations, rapes, and deaths. Participants, particularly the youths, had lived under the constant threat of abduction by the LRA and many had been forced to serve as (child) soldiers. The rural communities had been forcibly evacuated to protect members from the LRA, whereas the peri-urban and urban communities were confronted with an influx of refugees. Life in IDP camps was considered extremely harsh and characterized by deplorable living conditions and many social difficulties. Since 2006, various governmental and nongovernmental programs such as resettlement of IDPs, reconstruction of roads and schools, food provision, medical assistance, and peace talks have been carried out in these communities to promote postconflict reconstruction and reconciliation. The situation improved steadily after the war ceased and displaced people started to return to their original communities, but challenges such as poverty, health problems, limited educational opportunities, and land conflicts persist in these communities to date.

Based on the sociodemographic information gathered during the transect walk in the first phase of the research, all community members who consented to participate were assigned to predefined groups of stakeholders, demarcated by age and status. Youth groups consisted of community members aged 12-25 years, parent groups of community members with children aged 12-25 years, and other community member groups of elders (over 55 years of age), leaders (in a religious, cultural, or political leadership position), and teachers (teaching at local secondary schools). Participants were randomly sampled from these strata and invited to participate in the PRM sessions. This sampling method allowed us to take account of the perspectives of different stakeholders in the community. The sample consisted of 16 groups involving a total of 117 participants, half of whom were youths (eight groups, $n=60,51 \%$ ). About $40 \%$ of the young participants and $17 \%$ of the adult participants had been recruited by the LRA. Gender was fairly equally represented in the sample ( $n=67 ; 57 \%$ females). Participants had a mean age of 32.5 $(S D=18.9)$ years; youth averaged $17.1(S D=3.5)$ years old and adult participants (parents, leaders, elders, teachers), $44.7(S D=17.0)$ years old.

\section{Data analysis}

The results from the different PRM groups were collated to provide an overview of all the indicators that were generated. This resulted in a composite list of 132 items, representing the additive count of answers across all groups. Conceptually identical indicators were merged and, where relevant, rephrased to better represent the content of discussions. Six identified indicators were split because they contained overarching information that was in other groups presented separately (e.g., "looking smart"111 and "maintaining hygiene" was counted for "looking smart" and "being hygienic"). Further clustering of the indicators was not attempted (until the qualitative data were thematically analyzed in a later phase) in order to preserve a detailed conceptualization of resilience that could be used to develop measures of resilience in prospective studies. For each indicator, the frequency (number of 
times the indicator was placed on the pile) and rank (average ranking position of the indicator over various sessions) were calculated. For indicators that were placed on the pile only once, the qualitative data were explored in depth to identify whether other groups' discussions corroborated these indicators without the groups having explicitly selected them. Support was found for all indicators. Qualitative data were thematically analyzed by two researchers to search for patterned responses and meaningful themes that served to enhance understanding of indicators and their significance in conceptualizing resilience. Thematic analysis is a recursive process that involves distinct analytic phases: familiarization with data; generating initial codes; searching for themes among codes; reviewing themes; defining and naming themes; and producing a collated report (Braun \& Clarcke, 2006). This study applied an inductive approach as the identification and interpretation of themes was data-driven, and was situated only on a semantic level because the analysis focused on explicit meanings (Boyatzis, 1998). This process was facilitated by using NVivo 10 (QSR International Pty Ltd. Version 9, 2010), software for qualitative data analysis.

\section{Results}

Table 1 presents the indicators that were generated across the groups, and the frequency and median ranking position for each. Among the most frequently endorsed indicators of young people's resilience were "being educated/in school," "being healthy," "generating income," and "looking smart" (selected by at least half of the participants). When looking at the prioritizing of the most frequently selected indicators in the ranking exercises, "being close to God" was evaluated as the most crucial, followed by "being healthy" and "having money," and "being educated/in school." Comparing the results between the stakeholder groups shows clear consensus (high frequency and ranking) on the essential role of education and health. Most indicators were identified and equally ranked by both youths and other participants. However, the indicators "living in peace with other people," "receiving help from relatives," "being part of a group," and "being able to express yourself to other people" were prioritized by youths but not identified by the other groups. The latter assigned relatively more importance to indicators such as "having money/wealth," "eating a balanced diet," "living in a good house," and "meeting basic needs" compared to the youth groups. When analyzing the rationales behind the identified indicators, the following overarching six themes were central: progress; self-reliance; social connection; morality; health; and comfort.

\section{Progress}

A central theme in participants' explanations of the meaning and importance of several identified indicators was making progress in life. There were indicators showing that progress has been made in comparison with the situation during and immediately after the conflict (e.g., living in a good house, looking smart, 
Table I. Overview, frequency, and average rank of resilience indicators

\begin{tabular}{|c|c|c|c|c|c|}
\hline No & Indicator & Frequency & $\begin{array}{l}\text { Median } \\
\text { rank }\end{array}$ & $\begin{array}{l}\text { Median rank } \\
\text { youth }\end{array}$ & $\begin{array}{l}\text { Median } \\
\text { rank others }\end{array}$ \\
\hline I & Being educated/in school & 14 & 2.5 & 2 & 3 \\
\hline 2 & Being healthy & 13 & 2 & 3 & 2 \\
\hline 3 & $\begin{array}{l}\text { Doing a paid job/receiving a salary/ } \\
\text { generating income }\end{array}$ & 9 & 5 & 5 & 5 \\
\hline 4 & $\begin{array}{l}\text { Looking smart (having material } \\
\text { needs met/nice clothes) }\end{array}$ & 8 & 4 & 4 & 5 \\
\hline 5 & $\begin{array}{l}\text { Behaving respectfully towards } \\
\text { others/having good manners }\end{array}$ & 7 & 5 & 5 & 4.5 \\
\hline 6 & Associating/socializing with people & 6 & 5 & 3 & 6 \\
\hline 7 & Having and using skills and talents & 6 & 7.5 & 7 & 8 \\
\hline 8 & Having money/wealth & 5 & 2 & 6 & 1.5 \\
\hline 9 & Doing farming activities & 5 & 6 & 3 & 6.5 \\
\hline 10 & $\begin{array}{l}\text { Being close to God/believing/having } \\
\text { faith }\end{array}$ & 5 & 1 & I & 3 \\
\hline 11 & $\begin{array}{l}\text { Fitting well in the community } \\
\text { (community lifestyle, cultural } \\
\text { values) }\end{array}$ & 5 & 7 & - & 7 \\
\hline 12 & Eating a balanced diet & 4 & 3 & 5 & 2 \\
\hline 13 & $\begin{array}{l}\text { Having discipline (differentiate } \\
\text { between good and bad) }\end{array}$ & 4 & 7.5 & 9 & 6 \\
\hline 14 & Living in a good house & 3 & 3 & - & 3 \\
\hline 15 & $\begin{array}{l}\text { Having means of transport (bicycle, } \\
\text { car, etc.) }\end{array}$ & 3 & 8 & 7 & 9 \\
\hline 16 & Running a good business & 3 & 5 & 6 & 5 \\
\hline 17 & Having many friends/being popular & 3 & 3 & 6.5 & 3 \\
\hline 18 & Living in peace with other people & 3 & 2 & 2 & - \\
\hline 19 & $\begin{array}{l}\text { Helping other people (knowledge } \\
\text { sharing, advise, etc.) }\end{array}$ & 3 & 4 & 4 & 7 \\
\hline 20 & Receiving help from relatives & 2 & 2.5 & 2.5 & - \\
\hline 21 & $\begin{array}{l}\text { Sharing properties with other } \\
\text { people }\end{array}$ & 2 & 7 & 7 & - \\
\hline 22 & $\begin{array}{l}\text { Being hygienic and taking care of } \\
\text { sanitation }\end{array}$ & 2 & 6.5 & 6 & 7 \\
\hline 23 & $\begin{array}{l}\text { Being free of worries, fear, and } \\
\text { mental problems }\end{array}$ & 2 & 8.5 & 10 & 7 \\
\hline 24 & Doing leisure activities & 2 & 6 & 7 & 5 \\
\hline 25 & $\begin{array}{l}\text { Engaging in storytelling/informal } \\
\text { education }\end{array}$ & 2 & 8.5 & - & 8.5 \\
\hline
\end{tabular}


Table I. Continued

\begin{tabular}{|c|c|c|c|c|c|}
\hline No & Indicator & Frequency & $\begin{array}{l}\text { Median } \\
\text { rank }\end{array}$ & $\begin{array}{l}\text { Median rank } \\
\text { youth }\end{array}$ & $\begin{array}{l}\text { Median } \\
\text { rank others }\end{array}$ \\
\hline 26 & Feeling emotionally stable & 2 & 6 & - & 6 \\
\hline 27 & $\begin{array}{l}\text { Feeling safe and secure in the } \\
\text { environment }\end{array}$ & 2 & 4 & - & 4 \\
\hline 28 & Having many girl/boyfriends & I & 7 & 7 & - \\
\hline 29 & Having a big stomach & I & 8 & 8 & - \\
\hline 30 & Cooperating with others & I & 9 & 9 & - \\
\hline 31 & Having many properties & I & 4 & 4 & - \\
\hline 32 & Being part of a group & I & 1 & 1 & - \\
\hline 33 & Meeting basic needs & I & 4 & - & 4 \\
\hline 34 & $\begin{array}{l}\text { Having good relationship with the } \\
\text { caretakers }\end{array}$ & I & 5 & - & 5 \\
\hline 35 & $\begin{array}{l}\text { Getting inspired to move forward in } \\
\text { future }\end{array}$ & I & 7 & 7 & - \\
\hline 36 & $\begin{array}{l}\text { Being able to express yourself to } \\
\text { other people }\end{array}$ & I & 2 & 2 & - \\
\hline 37 & $\begin{array}{l}\text { Being able to care for yourself and } \\
\text { protect yourself }\end{array}$ & I & 6 & 6 & - \\
\hline 38 & Accessing the basic human rights & I & 5 & - & 5 \\
\hline 39 & $\begin{array}{l}\text { Being encouraged by others (family } \\
\text { and friends) }\end{array}$ & I & 3 & 3 & - \\
\hline 40 & Having means of communication & I & 8 & 8 & - \\
\hline
\end{tabular}

running a good business). Other indicators reinforced the idea that the present situation provides the basis for future progress through access to resources. The creative and decisive employment of resources for self-empowerment was perceived as typifying youth who are coping adaptively with the aftermath of war. Therefore, acquiring abilities and resources that initiate progress and open possibilities for the future was associated with an improved standard of living and well-being (e.g., having and using skills and talents, doing farming activities). Youth who are inspired to move forward in the future, even if they were not doing so at present, were also seen as doing well because they have hope for the betterment of their situation and courage to work on their future. As such, being offered/having and perceiving opportunities was deemed crucial for making progress in life (e.g., being close to God, cooperating with others). The importance of progressing is illustrated in the following extract:

To me, I feel that I am doing well because if I compare today and yesterday, there is a difference. All the time there is a difference. During those days, I was not even in 
school but today, being in Senior 3 like me ... if I go back to Primary, I can now teach there. So there is much difference between me and someone who has no studies... The knowledge I have is always useful and makes me to do well and even do better. (Youth)

\section{Self-reliance}

A number of indicators were considered key to resilience because they revealed that a young person is self-reliant. According to the participants, these indicators show that youths are able to care for and protect themselves and their relatives (e.g., doing a paid job, helping other people). Moreover, resilient youths were said to acquire knowledge and skills that allow them to promote their own health and wellbeing (e.g., being hygienic and taking care of sanitation). They further know how to differentiate between good and bad, are disciplined and responsible, and show moral behaviors (e.g., having discipline). Resilient youths also make something out of the opportunities or assets they have, in a way that promotes their self-reliance and thus their well-being as well as that of their relatives. They are deemed to be self-maintaining and independent, and at the same time to know how to obtain support from other people when needed (e.g., engaging in storytelling/informal education, being able to express yourself to other people). The latter idea of resilient youth is articulated in the following extract:

Now I can see that I am also doing well because I am able to speak. Maybe when I come to town and I find someone who is not from my tribe, I might be able to express myself so that if I have a problem and there is someone who doesn't understand my language, he is able to help me. So my knowledge in English helps me to express myself, so that someone can help me. (Youth)

\section{Social connection}

A third theme was the social connectedness of young people. Youth who are doing well were said to associate and socialize with other people, be part of a social group and to participate in social activities. For many participants, the way in which young people interact with others marks resilience (e.g., associating with people, behaving respectfully towards others, sharing properties with other people, being part of a group), as is evident in the following extract:

You can see that they are doing well when they are freely interacting with other children. Those who have been in the bush for some time [formerly recruited youths], when they are interacting freely with other children, they share common things. Maybe when they have a problem, they freely talk to them. That's how you can now know that they are doing well. (Teacher) 
It was argued that youths not feeling emotionally well or healthy tend to isolate themselves, and that other people will not befriend such youths easily or will talk negatively about them, hence jeopardizing their social connectedness. The participants' arguments highlighted that social connectedness implies benefits for the youths as well as for their social network and broader community. Young people with a solid social network and strong social connections were perceived to cope better with difficulties they experience, to have better outcomes of the efforts they make, and to experience increased social resources and support. In addition, they were seen as contributing to the well-being of others they associate with or help, their family, their community, and society at large.

\section{Morality}

A number of indicators that were consistently selected and ranked by various groups were related to morality. This involved, as one group of community members described it, the notion that "the child is able to know the do's and don'ts in the community and the commandments what he is supposed to do in his or her life." Participants identified house rules (e.g., having good relationship with the caretakers), social norms and expectations (e.g., behaving respectfully towards others), law and order (e.g., living in peace with other people), and cultural values and practices (e.g., fitting well in the community) as moral frameworks that resilient youth live by. This was particularly emphasized for young people who had been recruited by the LRA, because they were believed to have assumed another morality and lifestyle that did not represent that of the community. Morality was also associated with living conditions that were preventive of undesirable behaviors and life styles such as thievery, prostitution, domestic violence, and child abuse. Morality was also believed to benefit the family, community, and clan of these youths, as the following extract illustrates:

The child who is doing well is always well-disciplined and can listen to his parents and the community, can even abide by the rules and regulations or the norms of the community. When there is discipline and respect, even in the families you don't get any problems because your child can listen to you. There is always development in that house or that family. (Community member)

\section{Health}

The majority of groups identified health as a key indicator of resilience, referring principally to physical healthiness. However, when we probed further what health entailed for the participants, the typical answer was that "when we are talking about health, I think it also covers those areas emotional, physical, even spiritual" (Youth). Physical health, growth, and development were observed in youth who are able to maintain their health status by applying health precautions and 
accessing health measures and services (e.g., having a big stomach, being hygienic, and taking care of sanitation). Physical health was linked to mental health because pain and diseases as well as the lack of improvement or assistance with health problems prevent youths from feeling emotionally well. In contrast, resilient young people always looked happy and did not let anything affect their happiness because they were able to deal with challenges they faced, illustrating their emotional stability (e.g., being free of worries, fear, and mental problems; feeling emotionally stable). A sense of safety and security was also deemed crucial to mental health, particularly with reference to having experienced insecurity and danger caused by the insurgency. Spiritual health was important for resilience because religious young people seemed to better deal with mental distress and setbacks, and to have more strengths and hope in life (e.g., being close to God). Finally, participants emphasized that health was a precondition to do anything else: "when you're healthy, you have the opportunity to do everything" (Community member).

\section{Comfort}

Some indicators were deemed important because they show that a young person is living comfortably and can afford the necessary, basic human requirements that make life more comfortable. This is illustrated in the following extract:

Maybe somebody here in the community has a motorcycle and when someone is sick, they call you anytime to take this person to the hospital. So anyway you go, people look at you because life is easy for you and you are doing well. (Youth)

These indicators reflect the notion that young people who were doing well do not have to worry or struggle for their survival, unlike other youths who could not meet their basic needs and found it hard to enjoy things. Participants thus referred to more tangible signifiers of comfort (e.g., having money, doing a paid job, having a big stomach) as well as a comfortable state of mind (e.g., being free of worries, fear, and mental problems). Comfort was associated with freedom, because "that means people can see that you have freedom, or they can see that the wind is blowing you" (Youths). When prompted, the participants agreed that these indicators were not necessary, but endowed youth with a buffer to deal with challenges or setbacks, hence they were important indicators of youth resilience.

\section{Discussion}

This study aimed to explore contextually grounded indicators of young people's resilience in the aftermath of war, with a particular focus on positively valued functioning. It employed a participatory ranking methodology in four northern Ugandan communities in order to include perspectives of different stakeholder groups. The results show that the identified indicators cover a multiplicity of life domains, including education, livelihood, physical health, mental health, social and 
cultural life, and spirituality. This emphasizes the multidimensional character of well-being and suggests that resilience is situated at the intersection of various areas of functioning (Stark et al., 2009). The scope of these indicators thus reaches well beyond the predominant focus on absence of psychopathology as the key indicator of resilience (Barber, 2013; Tol et al., 2013). Recent literature presents disparate views on whether resilience is a generalized phenomenon that can be observed across several domains or is specific to particular domains of functioning (Barber, 2013; Layne et al., 2007; Luthar et al., 2000). The findings of this study suggest the need for an intersectoral and holistic approach that assesses multiple domains of functioning and aspects of well-being (Ager et al., 2013; Akello et al., 2010; Masten, 2007; Rutter, 2012).

The indicators we identified relate mainly to postconflict challenges and refer to how young people have been able to deal with displacement, disruption, and loss caused by the war. Warfare exposes youth to stressful experiences with consequences that usually extend beyond the end of hostilities, challenging young people to come to terms not only with endured war-related violence but also with deplorable living conditions and social disruption (Pedersen, 2002). Postconflict living conditions may compound the risk for adverse psychological consequences (Betancourt, 2013). In postwar northern Uganda, participants thought of resilient youth as young people who are able to progress, demonstrate self-reliance, are socially connected to others, live up to important moral frameworks, maintain their health, and experience comfort despite the experience of ongoing difficulties and resource-restricted context. Many indicators, such as being educated/in school, participating in farming activities, feeling safe and secure in the environment, and eating a balanced diet are not easily attained in postconflict settings where schools have been destroyed or closed, land has been lost, mobility is restricted due to safety reasons, and food is scarce. The indicators thus reflect an ability to deal with a constellation of challenges directly resulting from exposure to war or indirectly exacerbated by the prolonged and brutal armed conflict in this region. This testifies to the long-term detrimental consequences of warfare on the lives of young people in a postconflict setting, which forms the backdrop against which we can interpret the importance of the emerging resilience indicators. The identified indicators represent both the absence of negatively valued functioning (pathogenesis, e.g., being free of worries, fear, and mental problems) and the manifestation of positively valued functioning (salutogenesis, e.g., being able to express yourself to other people). This finding indicates that the positively and negatively valued aspects of functioning are inextricably intertwined and are both key to the conceptualization of resilience (Barber, 2013; Kaplan, 2005; Luthar, 1991; Tol et al., 2013). This suggests that future resilience research should focus not solely on the absence of negatively valued functioning but also on the strengths, capacities, and resources that signify positively valued functioning.

Many studies investigating positively valued functioning have been devoted to coping with stress after adverse experiences. The present study, however, suggests 
that youths' pathways to resilience are not solely based on their own efforts to deal with stressful experiences but are strongly related to their environment's progress towards well-being in the aftermath of armed conflict. These interconnections between the individual and the collective world strongly influence wellbeing. The indicators we identified concern not only the well-being of the individual but also the welfare of the family, community, and society. This finding may be illustrative of the collectivism of the Lango sociocultural context, in which the well-being, harmony, and unity of the collectivity is highly valued and individual members tend to define their well-being along lines of kinship, ancestry, and community (Atim \& Proctor, 2013). While resilience has typically been defined in individual terms and indicators (Ungar \& Liebenberg, 2011), our findings reinforce the notion of an interplay between individual and contextual processes in the construction of resilience in the context of northern Uganda. This implies that conceptualization and operationalization of resilience should reach beyond the individual level and include the context in which individuals are embedded. This provides some support for the emerging concepts of "community resilience" and "ecological resilience" (Ager et al., 2013; Norris, Stevens, Pfefferbaum, Wyche, \& Pfefferbaum, 2008; Saul, 2013; Tol et al., 2009; Wessells, 2012). These concepts emphasize that resilience applies to systems, involving families, communities, or broader social ecologies, and refers to the process of collective reflection, planning, and action to deal with encountered disturbances and challenges that may threaten or actually affect individual and communal well-being.

The indicators generated by participants in this study show some overlap with other studies reporting culturally sensitive conceptualizations of resilience, wellbeing, or mental health (Ager, Akesson, et al., 2011; Harms, Kizza, Sebunnya, \& Jack, 2009; Stark et al., 2009; Ungar \& Liebenberg, 2011). For instance, sociability is consistently identified as an important indicator of youth well-being across different studies and contexts. Nonetheless, other indicators represent contextually specific indicators of well-being that may not be present or recognized elsewhere, such as the importance of having a "big stomach" or "looking smart" as characteristics of resilient youths' physical appearance. Indicators linking resilience to livelihood and assets may be related to the fact that the Lango are an agro-pastoral people who suffered impoverishment and restrictions in economic self-reliance because of the war (Atim \& Proctor, 2013). This finding corroborates the idea that the construct "resilience" is partly universal and partly culturally variable (Ungar \& Liebenberg, 2011). Further conceptualizations of resilience should thus not solely incorporate etic (universal) but also emic (culture-specific) understandings of well-being amidst significant adversity. This finding further suggests that the contextually specific way of conceptualizing constructs such as resilience is strongly influenced by a range of discourses operating within the given culture and society, as these discourses seem to color which features, realities, and experiences are deemed resilient in the context of warfare. This study led to a conceptualization of resilience that intersects with notions of adaptive and normative functioning as 
defined in the specific research setting, suggesting that the evaluation of one's response to adversity as adaptive or problematic is based on whether one's functioning meets normative expectations (Barber, 2013; Bonanno, 2004; Boothby, Strang, \& Wessells, 2006; Kaplan, 2005).

Additional information collected during the ranking part of the PRM helped us to understand the interrelatedness of indicators. This complexity became apparent during the thematic analysis, as it appeared that most indicators were associated with multiple meanings and themes. The central themes presented in this manuscript should thus not be interpreted as latent constructs that cause the indicators to manifest but as an attempt to structure the multiplicity of meanings ascribed to the indicators. This calls for representations of resilience that capture its complexity, multiplicity, and nonlinearity. It is unlikely that the indicators generated in this study are exhaustive and capture the intricacies of resilience in this context.

Notwithstanding the probability sampling method and the consistency in the results, it is possible that the findings of this study mainly reflect the perspective of the four selected communities and groups of stakeholders. The pattern of responses suggests there may be some divergent perceptions of resilience indicators among different stakeholder groups within the communities. Comparison of indicators revealed that youths attribute relatively more importance to social-emotional indicators, while other stakeholders emphasize material indicators. However, most indicators were equally endorsed and a general consensus emerged on the importance of primordial markers of youths' resilience in northern Uganda. For instance, education and health were prioritized across different groups, suggesting that school enrolment and health promotion may be key strategies to foster resilience. Despite the advantages of using a group interview format to grasp a general, shared perspective, the findings may have been biased by the group perspective or social desirability. For this reason, future research should explore the relevance of these indicators in other populations and settings to triangulate and substantiate the findings (Kazdin, 2003). More PRM sessions might have yielded additional indicators, but it appears that this study captured some of the most important contextspecific markers of war-affected youths' resilience. To offset potential conceptual constraints, it is recommended that these indicators be used in combination with other measures that assess complementary facets of resilience (Kazdin, 2003).

Despite these limitations, this study represents a preliminary attempt to shed light on contextually grounded understandings of resilience and reveals indicators that can help to conceptualize and operationalize resilience in a more culturally sensitive way. The participatory approach allowed exploration of contextually grounded understandings and indicators of resilience, and hence holds promise for future contextually sensitive studies of resilience. Moreover, it enabled communities to engage in a shared reflection process and increase awareness of important signifiers of youths' well-being in the wake of war. This methodology may mobilize and empower communities to think, plan, and act collectively to foster young people's well-being and resilience. The participatory research process itself may thus have supported community resilience. 


\section{Acknowledgements}

The authors gratefully acknowledge the help of Ellen Vlayen, Giara Reynvoet, and Sanne Schrijvers in the data collection and the assistance of the Centre for Children in Vulnerable Situations (CCVS) staff in Lira, and wish to thank the community members for participating in this research.

\section{Funding}

This study did not receive a specific research grant, but financial support from Vlaamse Interuniversitaire Raad - Universitaire Ontwikkelingssamenwerking (VLIR-UOS) and the Peacebuilding Service of the Belgian Federal Public Service Foreign Affairs, Foreign Trade and Development Cooperation.

\section{Note}

1. "To look smart" is used in Uganda to describe one's physical appearance and refers mainly to looking beautiful/handsome and neat.

\section{References}

Ager, A. (1997). Tensions in the psychosocial discourse: Implications for the planning of interventions with war-affected populations. Development in Practice, 7(4), 402-407.

Ager, A. (2013). Annual Research Review: Resilience and child well-being - Public policy implications. Journal of Child Psychology and Psychiatry, 54(4), 488-500.

Ager, A., Akesson, B., Stark, L., Flouri, E., Okot, B., McCollister, F.,...Boothby, N. (2011). The impact of the school-based Psychosocial Structured Activities (PSSA) program on conflict-affected children in northern Uganda. The Journal of Child Psychology and Psychiatry, 52(11), 1124-1133.

Ager, A., Annan, J., \& Panter-Brick, C. (2013). Resilience: From conceptualization to effective intervention. Policy brief for humanitarian and development agencies. New York, NY: International Rescue Committee.

Ager, A., Stark, L., Sparling, T., \& Ager, W. (2011). Rapid appraisal in humanitarian emergencies using participatory ranking methodology (PRM). New York, NY: Columbia University Mailman School of Public Health Program on Forced Migration and Health.

Akello, G., Reis, R., \& Richters, A. (2010). Silencing distressed children in the context of war in northern Uganda: An analysis of its dynamics and its health consequences. Social Science and Medicine, 71, 213-220.

Annan, J., Blattman, C., \& Horton, R. (2006). The state of youth and youth protection in northern Uganda: Findings from the survey for war-affected youth. Kampala, Uganda: UNICEF and AVSI Uganda.

Atim, T., \& Proctor, K. (2013). Modern challenge to traditional justice: The struggle to deliver remedy and reparation in war-affected Lango. Medford, MA: Feinstein International Centre, Tufts University.

Attanayake, V., McKay, R., Joffres, M., Singh, S., Burkle, F. M., \& Mills, E. (2009). Prevalence of mental disorders among children exposed to war: A systematic review of 7,920 children. Medicine, Conflict \& Survival, 25, 4-19.

Barber, B. K. (2013). Annual Research Review: The experience of youth with political conflict-challenging notions of resilience and encouraging research refinement. The Journal of Child Psychology and Psychiatry, 54(4), 461-473. 
Barenbaum, J., Ruchkin, V., \& Schwab-Stone, M. (2004). The psychosocial aspects of children exposed to war: Practice and policy initiatives. Journal of Child Psychology and Psychiatry, 45(1), 41-62.

Betancourt, T. (2013). The social ecology of resilience in war-affected youth: A longitudinal study from Sierra Leone. In M. Ungar (Ed.) The social ecology of resilience. A handbook of theory and practice (pp. 347-356). New York, NY: Springer.

Betancourt, T. S., \& Kahn, K. T. (2008). The mental health of children affected by armed conflict: Protective processes and pathways to resilience. International Review of Psychiatry, 20, 317-328.

Bolton, P., \& Tang, A. M. (2002). An alternative approach to cross-cultural function assessment. Social Psychiatry and Psychiatric Epidemiology, 37, 537-543.

Bonanno, G. A. (2004). Loss, trauma and human resilience. Have we underestimated the human capacity to thrive after extremely aversive events? American Psychologist, 59(1), 20-28.

Boothby, N., Strang, A., \& Wessells, M. (2006). A world turned upside down: An ecological approach to children in warzones. Bloomfield, CT: Kumarian Press.

Boyatzis, R. (1998). Transforming qualitative information: Thematic analysis and code development. Thousand Oaks, CA: Sage.

Braun, V., \& Clarcke, V. (2006). Using thematic analysis in psychology. Qualitative Research in Psychology, 3, 77-101.

Camfield, L., Crivello, G., \& Woodhead, M. (2009). Wellbeing research in developing countries: Reviewing the role of qualitative methods. Social Indicators Research, 90, 5-31.

Chambers, R. (1995). Rural appraisal. Rapid, relaxed and participatory. In A. Mukherjee (Ed.) Participatory rural appraisal. Methods \& applications in rural planning. Essays in honour of Robert Chambers (pp. 1-86). New Delhi, India: Vikas Publishing House.

Coalition to Stop the Use of Child Soldiers. (2008). Child soldiers. Global report 2008. London, UK: Author.

Finnström, S. (2008). Living with bad surroundings. War, history and everyday moments in Northern Uganda. Durham, NC: Duke University Press.

Goodhand, J., \& Hulme, D. (1999). From wars to complex political emergencies: Understanding conflict and peace-building in the new world disorder. Third World Quarterly, 20(1), 13-26.

Harms, S., Kizza, R., Sebunnya, J., \& Jack, S. (2009). Conceptions of mental health among Ugandan youth orphaned by AIDS. African Journal of Aids Research, 8(1), 7-16.

Haroz, E. E., Murray, L. K., Bolton, P., Betancourt, T., \& Bass, J. K. (2013). Adolescent resilience in Northern Uganda: The role of social support and prosocial behavior in reducing mental health problems. Journal of Research on Adolescence, 23(1), 138-148.

Honwana, A. (1997). Sealing the past, facing the future: Trauma healing in Mozambique. Accord No. 3, special edition on the Mozambican peace process. London, UK: Coalition Resources.

Jordans, M. J., Tol, W. A., Komproe, I. H., \& De Jong, J. V. (2009). Systematic review of evidence and treatment approaches: Psychosocial and mental health care for children in war. Child and Adolescent Mental Health, 14(1), 2-14.

Kaplan, H. B. (2005). Understanding the concept of resilience. In S. Goldstein, \& R. B. Brooks (Eds) Handbook of resilience in children (pp. 39-47). New York, NY: Springer. 
Kazdin, A. E. (2003). Assessment. In A. E. Kazdin (Ed.) Methodological issues and strategies in clinical research (3rd ed., pp. 199-204). Washington, DC: American Psychological Association.

Kirmayer, L. J., Dandeneau, S., Marshall, E., Kahentonni Phillips, M., \& Jessen Williamson, K. (2012). Toward an ecology of stories: Indigenous perspectives on resilience. In M. Ungar (Ed.) The social ecology of resilience. A handbook of theory and practice (pp. 399-414). New York, NY: Springer.

Klasen, F., Oetingen, G., Daniels, J., Post, M., \& Hoyer, C. (2010). Posttraumatic resilience in former Ugandan child soldiers. Child Development, 81(4), 1096-1113.

Layne, C. M., Warren, J., Watson, P., \& Shalev, A. (2007). Risk, vulnerability, resistance, and resilience: Towards an integrative model of posttraumatic adaptation. In $\mathrm{M}$. J. Friedman, T. M. Kean, \& P. A. Resick (Eds) PTSD: Science \& practice: A comprehensive handbook (pp. 479-520). New York, NY: Guilford.

Luthar, S. S. (1991). Vulnerability and resilience: A study of high-risk adolescents. Child Development, 62, 600-616.

Luthar, S. S., Ciccetti, D., \& Becker, B. (2000). The construct of resilience: A critical evaluation and guidelines for future work. Child Development, 71, 543-562.

Masten, A. S. (2007). Resilience in developing systems: Progress and promise as the fourth wave rises. Development and Psychopathology, 19, 921-930.

McAdam-Crisp, J. L. (2006). Factors that can enhance and limit resilience for children at war. Childhood, 13, 459-477.

Norris, F. H., Stevens, S. P., Pfefferbaum, B., Wyche, K. F., \& Pfefferbaum, R. L. (2008). Community resilience as a metaphor, theory, set of capacities, and strategy for disaster readiness. American Journal of Community Psychology, 41, 127-150.

NVivo 10 (Version 9) [Computer software]. QSR International Pty Ltd.

Panter-Brick, C., \& Eggerman, M. (2012). Understanding culture, resilience and mental health: The product of hope. In M. Ungar (Ed.) The social ecology of resilience. A handbook of theory and practice (pp. 369-386). New York, NY: Springer.

Pedersen, D. (2002). Political violence, ethnic conflict, and contemporary wars: Broad implications for health and social well-being. Social Science \& Medicine, 55, 175-190.

Rutter, M. (2005). Environmentally mediated risks for psychopathology: Research strategies and findings. Journal of the American Academy of Child and Adolescent Psychiatry, 44, 3-18.

Rutter, M. (2012). Resilience: Causal pathways and social ecology. In M. Ungar (Ed.) The social ecology of resilience: A handbook of theory and practice (pp. 33-42). New York, NY: Springer.

Saul, J. (2013). Collective trauma, collective healing: Promoting community resilience in the aftermath of disaster (Routledge Psychosocial Stress Series). New York, NY: Routledge.

Schultz, J.-H., Sorensen, P. M., \& Waaktaar, T. (2012). Ready for school? Trauma exposure and mental health in a group of war-affected Ugandan adolescents re-attending school. Scandinavian Journal of Educational Research, 56(5), 539-553.

Stark, L., Ager, A., Wessells, M., \& Boothby, N. (2009). Developing culturally relevant indicators of reintegration for girls, formerly associated with armed groups, in Sierra Leone using a participatory ranking methodology. Intervention, 1, 4-16.

Summerfield, D. (1999). A critique of seven assumptions behind psychological trauma programmes in war-affected areas. Social Science \& Medicine, 48, 1449-1462.

Tol, W. A., Jordans, M. D., Reis, R., \& de Jong, J. (2009). Ecological resilience: Working with child-related psychosocial resources in war-affected communities. In D. Brom, R. 
Pat-Horenczyk, \& J. D. Ford (Eds.), Treating traumatized children. Risk, resilience and recovery (pp. 164-182). New York, NY: Routledge/Taylor \& Francis Group.

Tol, W. A., Song, S., \& Jordans, M. J. (2013). Annual Research Review: Resilience and mental health in children and adolescents living in areas of armed conflict - A systematic review of findings in low- and middle-income contries. The Journal of Child Psychology and Psychiatry, 54(4), 445-460.

Ungar, M. (2011). The social ecology of resilience: Addressing contextual and cultural ambiguity of a nascent construct. Journal of Orthopsychiatry, 81(1), 1-17.

Ungar, M., \& Liebenberg, L. (2011). Assessing resilience across cultures using mixed methods: Construction of the Child and Youth Resilience Measure. Journal of Mixed Methods Research, 5(2), 126-149.

Vindevogel, S., Coppens, K., Derluyn, I., De Schryver, M., Loots, G., \& Broekaert, E. (2011). Forced conscription of children during armed conflict: Experiences of former child soldiers in northern Uganda. Child Abuse \& Neglect, 35(7), 551-562.

Vindevogel, S., De Schryver, M., Broekaert, E., \& Derluyn, I. (2013). Challenges faced by former child soldiers in the aftermath of war in Uganda. Journal of Adolescent Health, 52, 757-764.

Wessells, M. (2012). Psychosocial well-being and the integration of war-affected children: Toward a community resilience approach. In I. Derluyn, C. Mels, S. Parmentier, \& W. Vandenhole (Eds) Re-member. Rehabilitation, reintegration and reconciliation of war-affected children (pp. 57-75). Cambridge, UK: Intersentia.

Williams, R. (2007). The psychosocial consequences for children of mass violence, terrorism, and disasters. International Review of Psychiatry, 19(3), 263-277.

Wisner, B., \& Adams, J. (2002). Environmental health in emergencies and disasters: A practical guide. Geneva: Switzerland: World Health Organization.

Sofie Vindevogel, PhD, is postdoctoral assistant at the Department of Special Education at Ghent University in Belgium and is affiliated as a researcher to the Centre for Children in Vulnerable Situations. Her PhD study focused on former child soldiers in northern Uganda, addressing the question which challenges and resources these young people experience in their transition from military to civilian life, and which resources strengthen resilience in the aftermath of child soldiering. Her current research further explores how children, youth, families, and communities in (post)conflict situations cope with many different kinds of adversity, and which elements of their social ecology contribute to resilience.

Alastair Ager, PhD, is Professor of Population \& Family Health at Columbia University Medical Center in New York. He has worked in the field of global health and development for 25 years, after training in psychology at the universities of Keele, Wales, and Birmingham. He researches in the areas of refugee mental health, evaluation of humanitarian interventions, and the role of faith communities in supporting recovery. He is currently leading studies evaluating the impact of Child Friendly Spaces in emergencies in Ethiopia, Uganda, and Jordan; health systems resilience in contexts of crisis (including northern Nigeria); and a study of engagement of local faith communities in humanitarian response to the Syria crisis. 
Julie Schiltz, MSc, is a PhD student at the Department of Orthopedagogics at Ghent University and affiliated to the Centre for Children in Vulnerable Situations as a researcher. Her research focuses on the role of ongoing loss and gain of resources in the psychological wellbeing of South Sudanese refugee youth in northern Uganda.

Eric Broekaert, $\mathrm{PhD}$, heads the Department of Orthopedagogics (special education) at Ghent University, Belgium. He has a long experience in the field of substance abuse treatment and research, both nationally and internationally. Prof. Broekaert founded the first therapeutic community (TC; "De Kiem") in Belgium. He is the Chairman of the Orthopedagogical Observation and Treatment Centre for Children With Behavior Disorders, and of the European Workshop on Drug Policy Oriented Research. He is a board member of the European Scientific Association for Residential and Foster Care and of the Centre for Vulnerable Children. He is honoree Vice President of the European Federation of Therapeutic Communities. He is actively involved in a variety of national and international research projects concerning substance abuse treatment. He has authored numerous scientific publications, is Coeditor of Therapeutic Communities - The International Journal of Therapeutic Communities and widely recognized as an expert concerning the application of the TC for addictions.

Ilse Derluyn, $\mathrm{PhD}$, is Codirector of the Centre for Children in Vulnerable Situations and a Professor of Intercultural Pedagogics in the Department of Social Welfare Studies at Ghent University. Dr. Derluyn researches the psychosocial wellbeing of war-affected children, refugee children, and other migrant populations. She is currently involved in several studies in different countries around the world, and is part of different research networks on psychosocial wellbeing and health of refugee and war-affected children. Her published works focus mainly on psychosocial wellbeing of refugee and war-affected populations, including former child soldiers, unaccompanied refugee minors, minor victims of war-related sexual violence, victims of trafficking, and migrants returning to their home countries. 